\title{
PERAN DAN RESPON TASAWUF TERHADAP PROBLEMATIKA ERA MODERN
}

\author{
Dr. Amir Mahmud, M.Ag. \\ Universitas Nahdlatul Ulama Surakarta \\ doktoramir@gmail.com
}

\begin{abstract}
Abstrak
Tasawuf sebagai realitas peradaban islam hingga saat ini masih terus dipandang sebagai masalah yang mengundang kontroversi, dimana kelompok puritan radikal (salafi) menuduhnya sebagai bid'ah yang menyimpang dari ajaran Nabi Muhammad SAW. Sementara kaum modernis menudingnya sebagai biang kemunduran peradaban islam semenjak periode pertengahan. Disisi lain, tasawuf dimasa pertengahan mampu memainkan peranan yang besar untuk mempertahankan identitas dan nilai-nilai keislaman ketika sebagian besar negeri muslim dikuasai oleh penjajah barat. Dewasa ini tasawuf mengalami evolusi bentuk maupun institusi dan ditransformasikan dalam berbagai gerakan spiritualitas islam konstekstual guna menjawab kekeringan batin manusia modern melalui apa yang disebut sebagai Tasawuf Positif.
\end{abstract}

Kata Kunci : Spiritual, Suf, Tarekati

\begin{abstract}
Sufism as the reality of Islamic civilization until now still continues to be seen as a controversial issue, where radical puritan (salafi) accused him as a heresy that deviates from the teachings of Prophet Muhammad SAW. While the modernists have accused him as the culprit of the decline of Islamic civilization since the mid-period. On the other hand, the mysticism of tasawwuf can play a major role in maintaining Islamic identity and values when most Muslim countries are dominated by western invaders. Nowadays tasawwuf has evolved both forms and institutions and is transformed in various movements of contextual Islamic spirituality in order to respond to the modern inner drought through what is called Positive Sufism.
\end{abstract}

Keywords: Spiritual, Sufi, Tarekat

\section{PENDAHULUAN}

Umat Islam selaku pengikut nabi Muhammad SAW, meyakini bahwa kebenaran ajaran islam yang sempurna merupakan penggenapan janji Allah atas doa Al-Khalil Nabi Ibrahim AS, di Lembah Makkah yang memohon kepada Allah di hadapan ka'bah:

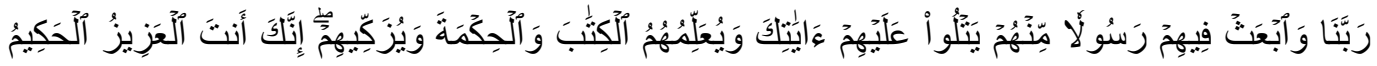

"Ya Tuhan kami, utuslah kepada mereka seorang Rasul dari kalangan mereka yang akan membacakan ayat-ayatMUdan mengajarkan Kitab (Al-Qur'an) dan 
hikmah serta mensucikan mereka. Sesungguhnya Engkaulah yang Maha Perkasa lagi Maha Bijaksana” ( QS Al-Baqarah : 129)

Maka Allah pun kemudian mengabulkan permohonanya dengan mengutus Muhammad SAW, tidak hanya sekedar untuk anak keturunan Nabi Ibrahim atau penduduk mekkah, melainkan bagi seluruh umat manusia sebagaimana disebutkan

"Dialah yang telah mengutus kepada kaum yang buta huruf seorang rosul dari kalangan mereka yang membacakan ayat-ayat-Nya dan mensucikan serta mengajarkan kepada mereka kitab dan hikmah. Dan Sesungguhnya, sebelumnya itu mereka benar-benar dalam kesesatan yang nyata. Dan (juga ) bagi kaum selain mereka yang belum berhubungan dengan mereka . Dan Dialah yang Maha Perkasa lagi Maha Bijaksana" (QS. Al-Jumuah : 2-3)

Maka kemudian perlu difahami adalah kesempurnaan dan kelengkapan Islam sebagai suatu ajaran Agama, yang tidak hanya sekedar mengatur hubungan antara sesama ciptaan Allah, sebagai pencerminan dari kedudukan manusia selaku wakil Tuhan atau Khalifatullah di muka Bumi. Oleh karena umat islam berkewajiban untuk mengatur seluruh aspek kehidupannya berdasarkan norma-norma islam yang bersumber dari Al-Qur'an dan sunnah, sebagaimana yang telah di contohkan oleh para sahabat, tabi'in dan kaum salaf yang shaleh. Salah satu tema yang termasuk di dalam ajaran islam adalah tema-tema yang berkenaan dengan pensucian jiwa, sebagaimana yang disebutkan di dalam ayat-ayat tersebut di muka.

Tema pensucian jiwa sebagai salah satu misi dari kerasulan Muhammad SAW di kalangan umat islam kemudian diimplementasikan dalam bentuk metode yang bernama tasawuf. keberadaan Tasawuf merupakan pengejawantahan nilai nilai spiritualitas Islam yang terlembagakan menjadi suatu sistem perilaku sekelompok umat islam tertentu yang merupakan realitas sejarah peradaban Islam yang tidak dapat di ingkari keberadaannya. Namun kontrovensi tentang tasawuf sudah muncul semenjak masa Ibnu Taimiyah hingga dewasa ini, dimana tidaklah seluruh umat Islam sepakat atas penamaan dan sistematika konsep yang terkandung di dalamnya, meskipun pada kenyataannya mereka mengamalkan perilaku kesufian praktis dalam kehidupan sehari hari. 


\section{METODE PENELITIAN}

Penelitian ini dilakukan melalui studi pustaka dengan mengumpulkan sejumlah buku-buku, makalah, jurnal, lefleat, majalah yang berkenaan dengan masalah pendidikan aliran klasik. Data yang diperoleh berasal dari dokumen pribadi yang berupa bahan-bahan orang yang mengucapan dengan kata-kata mereka sendiri (Arief Furqon, 1992: 23). Sehingga dalam pengumpulan data dengan mengidentifikasi wacana dari buku-buku, makalah atau artikel, majalah, jurnal, Koran, internet (web), ataupun informasi lainnya yang berhubungan dengan aliran pendidikan klasik. Adapun analisis data menggunakan analisis deskriptif, analisis isi, dan analsisis kritis. Analisis deskriptif yaitu mengumpulkan dan menyusun data kemudian dianalisis data tersebut. Analisis isi yaitu memanfaatkan seperangkat prosedur untuk menarik kesimpulan dari sebuah dokumen yang telah diperoleh. Sementara itu analisis kritis yaitu penafsiran pada teks dan menyikapi makna dibalik suatu peristiwa secara ilmiah.

\section{PEMBAHASAN}

Tasawuf secara etimologi merupakan perkembangan lanjut dari istilah "sufi" yang dikalangan para pengkaji terdapat banyak silang pendapat seputar maknanya. Ada yang mengatakan bahwa istilah "sufi" tersebut berasal dari kata "shofwun" yang berarti bening, ada pula yang menganggapnya berasal dari kata shaffyang artinya barisan, karena para sufi berada di barisan pertama di hadapan Allah. Sementara itu ada yang berpendapat bahwa kata tersebut di nisbatkan kepada Ahlus Shuffah yaitu sekelompok sahabat muhajirin dan anshar yang miskin yang tinggal dalam ruangan di sisi masjid Nabi SAW, yang mana mereka dikenal sebagai orang yang tekun beribadah. Pendapat yang lain mengatakan bahwa kata sufi berasal dari bahasa Yunani, Shophia yang berarti bijaksana. Namun kajian yang lebih mendalam membuktikan bahwa asal kata yang tepat ialah Shuffyang berarti wol, jenis bahan pakaian yang terbuat dari bulu domba. Konon pada masa awal 
asketisme, pakaian yang berbahandarin bulu dombabanyak digunakan oleh orang yang tulus dan asketis.

Tasawuf dalam bentukistilah baku memang belum dikenal pada zaman Nabi Muhammad SAW. Istilah ini lahir beberapa abad pasca masa hidup Rasulullah SAW. Namun sesungguhnya tasawuf ada dalam islam dan mempunyai dasar yang mendalam. Tidak dapat di ingkari dan disembunyikan dapat dilihat dan dibaca dalam Al-Qur'an, Sunnah Rasul SAW dan sejarah Kehidupan para sahabatnya yang mempunyai sifat-sifatZuhud (tidak mau atau menjauhi hubbub dunya), tidak suka hidup mewah, sebagaimana sikap Khalifah Umar RA, Ali RA, Abu Darda', Salman Al-Farisi RA, Abu Dzar RA dan lainnya.

Adapun tentang ilmu tasawuf, dalam kitab "Tanwiirul Quluub", Syaikh Amin Al-Kurdi menyebutkannya sebagai Ilmu untuk mengetahui tingkah laku jiwa, baik ituyang terpuji maupun yang tercela, bagaimana mensucikannya dari yang tercela dan menghiasinya dengan yang terpuji, serta bagaimana menempuh jalan menuju Allah dan berlari Kepada-Nya.

Akan tetapi ilmu tasawuf memang termasuk ilmu yang rentan untuk dipalsukan, bahkan nama tasawuf seringkali dipakai untuk melegitimasi sihir dan perdukunan. Sehingga saking seringnya ilmu ini dipalsukan, seolah-olah tasawuf menjadi identik dengan segala bentuk sihir, Khurafat, syirik dan Bid'ah. Ahli bid'ah dan golongan fasik banyak menyebut ilmu yang dikembangkannya sebagai ilmu tasawuf, bahkan menyebut dirinya sebagai ahli tasawuf. namun klaim seperti itu ditolak dan tidak diakui oleh tokoh-tokoh sufi yang benar dan terkenal, Seperti Junaid Al-Baghdadi (W.297 H) dan Ulama sufi lainnya.

Sesungguhnya ilmu tasawuf adalah ilmu tentang manajemen hati. Apa yang diangkat oleh AA Gym dengan Konsep Managemen Qolbu-nya tidak lain adalah reaktualisasi tasawuf sesuai dengan konteks perkembangan zaman yang dihadapi. ilmu tasawuf ada dalam Islam, serta merupakan bagian dari ajaran islam. Semua Imam dalam ilmu Fiqih pada dasarnya juga ahlidalam ilmu tasawuf. Imam AlGhozali adalah tokoh besar dalam ilmu tasawuf, ketika beliau menulis kitab Ikhya'u Uluum-ad-Diin. Bahkan Ibnul Qoyyim juga termasuk ulama yang mempunyai 
perhatian besar terhadap ilmu ini. Beliau berkata dari tokoh-tokoh sufi Al Junaid bin Muhammad dengan kata-katanya, "semua Jalan tertutup nagi manusia, Kecuali jalan yang dilalui Nabi Muhammad dengan kata-katanya ," semua Jalan tertutup bagi manusia, kecuali jalan yang dilalui Nabi SAW."

Ilmu tasawuf mengajarkan keikhlasan dan kebersihan hati dari sifat-sifat buruk. Diantaranya sifat riya', suka dipuji, sombong, ujub, kikir, sum'ah besar kepala, mau menang sendiri, hanya berorientasi, kepada kemegahan duniawi, tidak pernah salah, dan seterusnya. Ilmu tasawuf mengajarkan moral, nilai-nilai, akhlaq dan etika. Ilmu tasawuf mengajak orang bertaubat kepada Allah atas semua dosa dan kesalahan.

Sesungguhnya peranan tasawuf dalam islam adalah berusaha memperdalam kearah rohaniah, ubudiyah, dan perhatiannya tercurah seputar permasalahan itu. Hampir setiap agama di dunia ini memiliki ajaran spiritualitas yang menyerupai tasawuf, diantaranya dalam ajaran hindu ada konsep faqir, yaitu orang yang condong menyiksa diri sendiri dengan menjauhkan dari nikmat badani, demi membersihkan jiwa dan meningkatkan amal ibadahnya agar mencapai moksha. Dalam agama Kristen terdapat ajaran spirituallitas yang juga mirip tasawufkhususnya bagi para pendeta dan kaum biarawan yang melembaga menjadi ordo. Di Yunani muncul aliran Ruwagiyin, di Persia ada aliran yang bernama mani'dan di negeri-negeri lainnya banyak bermunculan aliran ekstrim dibidang spiritual.

Kemudian Islam datang dengan membawa perimbangan yang paling baik diantara kehidupan rohaniah dan jasmaniah serta penggunaan akal. Maka manusia sebagaimana digambarkan oleh agama terdiri dari tiga unsur: Roh, akal dan jasad. masing-masing dari tiga unsure itu wajib diberikan haknya sesuai dengan kebutuhannya. Ketika Nabi SAW melihat salah satu sahabatnya berlebih-lebihan dalam salah satu sisi ibadah, sahabat itu segera ditegur. Sebagaimana yang terjadi pada Abdullah bin Amr bin Ash. Ia Berpuasa terus menerus tidak pernah berbuka, sepanjang malam beribadat, tidak pernah tidur, serta meninggalkan isteri dan kewajibannya. 
Lalu Nabi SAW menegurnya dengan sabdanya, "Wahai Abdullah, sesungguhnya bagi dirimu ada hak (untuk tidur), bagi isteri dan keluargamu ada hak (untuk bergaul), dan bagi jasadmu ada hak. Maka masing-masing ada haknya. " Ketika sebagian dari para sahabat Nabi SAW bertanya kepada isteri-isteri Rasul SAW mengenai ibadah beliau yang luar biasa, para isteri rasulullah menjawab"Kami amat jauh dari nabi SAW yang dosanya telah diampuni oleh Allah SWT, baik dosanya yang telah lampau maupun dosa yang belum dilakukannya”. Kemudian salah seorang diantara mereka berkata "aku akan beribadah sepanjang malam”. Sedang yang lain mengatakan, "aku tidak akan menikah. Kemudian hal itu sampai terdengar oleh Rasulullah SAW, sehingga mereka dipanggil dan Rasulullah SAW berbicara dihadapan mereka.

Sabda beliau : "Sesungguhnya aku ini lebih mengetahui daripada kamu akan makrifat Allah dan aku lebih takut KepadaNya daripada kamu; tetapi aku bangun, tidur, berpuasa, berbuka, menikah dan sebagainya; semua itu adalah sunnah. Barang siapa yang tidak senang dengan sunnahku ini maka ia tidak termasuk golonganku”. Karenanya, Islam melarang melakukan hal-hal yang berlebih-lebihan dan mengharuskan mengisi tiap tiap waktu luang dengan hal-hal yang membawa manfaat, serta menghayati setiap bagian dalam hidup ini.

Berkembangnya ekonomi dan meningkatnya kemakmuran masyarakat mengakibatkan mereka terseret jauh dari apa yang dikehendaki oleh islam yang sebenarnya (jauh dari tuntutan islam).Iman dan ilmu agama menjadi falsafah dan ilmu kalam (perdebatan) ; dan banyak dari ulama-ulama fiqih yang tidak lagi memperhatikan hakikat dari segi ibadah rohani,. Mereka hanya memperhatikan dari segi lahirnya saja. Sekarang ini muncul dari golongan sufi yang dapat mengisi kekosongan pada jiwa masyarakat dengan akhlak dan sifat-sifat yang luhur serta ikhlas. Hakikat dari Islam dan Iman semuanya hamper menjadi perhatian dan kegiatan dari kaum sufi.

Para tokoh sufi sangat berhati-hati dalam meniti jalan diatas garis yang telah ditetapkan oleh Al-Qur'an dan As-Sunah. Bersih dari berbagai pikiran dan praktik yang menyimpang, baik dalam ibadah maupun dalam pemikirannya. Banyak orang 
yang masuk Islam karena pengaruh mereka, banyak orang yang durhaka dan lalim lantas kembali bertobat karena jasa mereka. Dan tidak sedikit yang mereka wariskan pada dunia Islam, yang berupa kekayaan besar dalam buah peradaban dan ilmu, terutama dibidang makrifat, akhlak dan pengalaman-pengalaman di alam rohani, yang kesemuanya itu tidak dapat di ingkari.

Tetapi ada pula diantara orang-orang sufi itu terlampau mendalami tasawuf hingga ada yang menyimpang dari jalan yang lurus dan mempraktekkan teori di luar islam, ini yang dinamakan Sathahat orang-orang sufi; atau perasaan yang halus dijadikan sumber hokum mereka. Pandangan mereka dalam masalah pendidikan diantaranya ialah seorang murid dihadapan gurunyaharus tunduk patuh ibarat mayat di tengah-tengah orang yang memandikannya. Akibatnya tasawuf yang semula memiliki tujuan baik yaitu kebersihan diri dan taqarrub kepada Allah melenceng dari batas apa-apa yang secara jelas telah diatur oleh Al-Qur'an dan As-Sunnah, baik dalam aqidah, pemahaman ataupun tata cara yang dilakukan. Namun demikian, tidak semua isi ajaran dalam pengalaman tasawuf itu mrupakan bid'ah dan sesat, selama tasawuf itu tetap berpegang pada dasar syari'at yang benar.

Banyak dari golongan ahlus sunnah dan ulama salaf yang menjalankan tasawuf, sebagaimana diajarkan oleh Al-qur'an dan banyak pula yang berusaha meluruskan serta mengkritisinya dengan timbangan Al-Qur'an dan As-Sunnah. Diantaranya ialah Imam Ibnu Al-Qayyim Al Jauzy yang menulis kitab yang berjudulMadaarijuz-saalikin ila manaazuluz-saairiinyang artinya "Tangga bagi perjalanan Menuju ke tempat Tujuan”. dalam buku tersebut diterangkan mengenai ilmu tasawuf, terutama dibidang akhlak, sebagaimana buku kecil karangan Syaikhul Islam al-Harawi al-Hanbali yang menafsirkan dari surat Al-Fatihah dengan judul Iyyaka Na'budu wa Iyyaka Nasta'in.

Kitab tersebut merupakan kitab yang paling baik bagi orang yang ingin mengetahui masalah tasawuf secara mendalam. Sesungguhnya tiap-tiap manusia boleh memakai pandangannya dan boleh tidak memakainya, kecuali ketetapan dan hokum-hukum yang bersumber dari Al Qur'an dan sunnah Rasulullah SAW. Kita dapat mengambil dari ilmu para sufi pada bagian yang murni dan jelas, misalnya 
ketaatan kepada Allah SWT, cinta kepada sesama makhluk, makrifat akan kekurangan yang ada pada diri sendiri, mengetahui tipu muslihat dari setan dan pencegahannya, serta perhatian mereka dalam meningkatkan jiwa ke tingkat yang murni.

Di samping itu, menjauhi hal-hal yang menyimpang dan terlampau berlebihlebihan, sebagaimana diterangkan oleh tokoh sufi yang terkenal yaitu Imam AlGhazali Rahimahumullah. Melalui Peran ulama ini kita dapat mengetahui banyak hal terutama kajian yang mendalam seputar ilmu akhlak, penyakit ruhani dan pengobatanya.

Sejalan dengan berkembangnya ilmu-ilmu Ke-Islaman, baik itu adalah Fiqih dan Ushl Fiqih dalam lapangan syari'ah, Ilmu kalam dan aqidah dalam lapangan keimanan, maka dalam lapangan Ilmu al-akhlak, tumbuhlah Ilmu tasawuf di kalangan ulama Abad ke III dan IV hijriyah. Perkembangan keilmuan yang sedemikian pesat iti, dibarengi dengan munculnya aliran-aliran metode pengajaran dan pengamalan akhlak salaf, yang akhirnya dikenal sebagai Thoriqoh atau di Indonesia disebut tarekat.

Tarekat didifinisikan sebagai "Pengamalan Syari'at dengan mengambil azimahnya menjauhkan diri dari penggampangan syari'at, atau boleh juga dikatakan sebagai menjauhi segala larangan lahir maupun batin dan mengerjakan segala perintah Ilahi sekuat tenaga dibawah bimbingan seorang arif yang mengetahui tujuan" (Amin al-Kurdi, tt, hal. 364)

Tarekat bisa berarti metodologi bertasawuf dan bisa pula berarti Organisasi tasawuf. Sayyid Muhammad Aqil dalam bukunya Dirasat fi at-Thuruq asshufiyah,menyatakan tarekat sebagai "sekumpulan etika dan akhlak yang menjadi pegangan kelompok sufi". Pendapat lain menyatakan bahwa yang dinamakan tarekat ialah "menjalankan agama islam dengan lebih hati-hati, sebagaimana menjauhi syubhat, menjalankan keutamaan-keutamaan sesudah kewajiban, seperti mengerjakan sholat tahajut, sunnah rowatib dan sebagainya. serta sungguh-sungguh dalam mengerjakan ibadah dan riadhoh, seperti puasa senin kamis, tadarrus, sholawat, dzikir dan sebagainya". 
Dengan demikian secara sederhana tarekat bisa kita definisikan sebagai "suatu metode tertentu untuk membersihkan jiwa agar bisa menjadi dekat kepada Allah SWT”. Guna memudahkan nmelakukan identifikasi metode pengajaran akhlak ini, maka masing-masing metode tersebut, dinisbatkan atau disandarkan kepada para tokohnya, seperti nama tarekat al-Qashsshariyyah dinisbatkan kepada Hamdun alQashshar, (W $271 \mathrm{H}$ ), tarekat Thaifurriyyah yang dinisbatkan kepada Abu Yazid al-Bhusthomi(W261 H), sebagaimana kita mengenal madzab Maliki yang di nisbatkan kepada Imam Malik dan Madzab Syafi'ie yang dinisbatkan kepada Imam Muhammad bin Idris As-Syafi'ie dalam lapangan ilmu Fiqih.

Selanjutnya sebagai organisasi Tasawuf perkembangan tarekatb dalam sejarah telah memunculkan banyak nama yang umumnya berhubungan dengan Nama Guru Perintisnya. Hal ini adalah sesuatu yang wajar karena sebagai organisasi tarekat adalah " Sekumpulan orang-orang sufi yang menisbatkan diri kepada Syaikh/Guru tertentu".

Nama-nama Tarekat yang muncul di abad 3\&4 Hijriyah antara lain;Malamatiyah, Thoifurriyah, Hallajiyah, dan Nurriyah. Kemudian di abad ke 5 muncul tarekat Ghazaliyah, selanjutnya disusul oleh tarekat Burhaniyyah, Qadiriyah, akhbariyyah, Rifa'iyyah, Syadziliyyah, Suhrawardhiyyah, Khalwatiyah dan lain-lain. Diantara nama-nama aliran tarekat yang masih memiliki banyak pengikut hingga saat ini adalah : Naqshabandiyyah, Tijaniyyah, Rifa'iyyah, Syadziliyyah, Qadiriyyah, Haddadiyyah, Syatariyyah dan Idrissiyah.

Dengan demikian tarekat merupakan bentuk praktis dari pendidikan tasawuf dimana para murid di didik dan dilatih untuk mengolah ruhaninya, agar memperoleh keridhaan Allah SWT. Inti dari pelajaran tarekat ialah merutinkan ingat kepada Allah atau yang dikenal sebagai aktifitas berdzikir. Melalui Dzikir, seseorang dilatih untuk mengurangi keburukan perilakunya dan menggantikannya yang baik, serta menjaga akhlak dihadapan siapapun. Dengan senantiasa mengingat Allah(Berdzikir) maka kita akan selalu sadar bahwa diri kita selalu diawasi oleh AllahSWT, sehingga kita benar-benar merasa takut untuk berbuat maksyiat, yang 
berarti secara perlahankeburukan perilaku kita akan terkikis satu semi satu. ini sesuai firman Allah yang berbunyi :

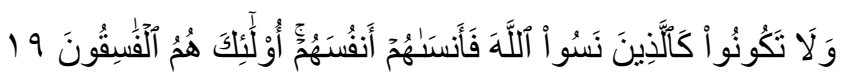

"Dan janganlah kalian ini seperti orang-orang yang telah lalai kepada Allah sehingga Allah jadikan mereka lupa diri. Mereka itu adalah orang-orang yang fasik" (QS Al-Hasyr : 19)

Pengertian Dzikir menurut pandangan para praktisi tarekat ialah menyebut nama Allah dengan mengucapkan kalimat-kalimat Toyyibah yang menjalar ke seluruh anggota tubuh, jiwa dan raga, sehingga benar-benar membekas di dalam hati dan diri pribadi dan menumbuhkan rasa cinta untuk melaksanakan semua perintah dan anjuran Allah dan sebaliknya merasa bahwa dirinya terancam jika akan mengerjakan kemaksyiatan yang dibenci oleh Allah dan Rasul-Nya. Orang yang melatih jiwanya dengan jalan mengolah jiwa atau ruhani ini harus mengikuti apa yang dicontohkan baginda Nabi Muhammad SAW beserta para sahabatnya dengan mengikhlaskan diri kepada Allah dan selanjutnya mereka dinamakan sebagai Ahlith-Thoriqoh.

Seorang Guru Tarekat yang bernama Ahmad Rifa'i dari Desa Kalisasak Batang menjelaskan pengertian tarekat kepada para muridnya gaya Nadhaman (bersyair) sebagai berikut:

Utawi tarekate wong dagang lan nandur

Yaiku arep neja ing Allah atine taat

Manfaate ati ginawe nulungi Ibadah

Netepi wajib ngedohi maksiat

Melalui Syair di atas Kyai Rifa'i menyampaikan bahwa yang disebut tarekat adalah ketaatan kepada Allah dengan mengerjakan ibadah dan segenap kewajiban serta menjauhi segala perbuatan maksiat. Seluruh aliran Tarekat yang ada di muka Bumi sungguh amat banyak dan tersebar di berbagai masyarakat Islam. Menurut beberapa kitab mengenai tarekat diperkirakan ada lebih dari 90 macam nama tarekat yang masih eksis tersebar di dunia Islam. Adapun menurut Jam'iyyah Ahlith 
Thoriqoh Indonesia, dari sekian banyak nama-nama tarekat yang ada yang di nilai mu'tabaroh atau terakreditasi ada 45 nama, berdasarkan kajian sanad yang mutashil (bersambung) hingga Rasulullah SAW dan ajaran-ajarannya dibakukan dalam buku-buku yang bisa dipercaya.

Walaupun masing-masing memiliki nama yang berbeda namun pada hakekatnya adalah satu juga, karena seluruh aliran tarekat yang sahih sanad keoilmuanya wajib bersambung silsilah hingga Nabi Muhammad SAW. Maka dengan demikian ajaran yang disampaikan dalam tarekat tidak boleh menyalahi isi kandungan Al-Qur'an dan suunah Rasul SAW. Dengan demikian yang menjadi tolak ukur bagi benar-tidaknya suatu ajaran tarekat dapat dengan mudah kita saksikan bagaimana cara mereka mengikuti sunnah Rasul SAW.

Dalam berbagai kitan ajaran tarekat yang kredibel, semacam kitab Tanwirul Quluub, dijelaskan bahwa "seorang pengamal tarekat harus berjalan diatas Kitab dan Sunnah serta mengikuti warisan para ulama". Dari sini dapatlah kita pahami bahwa amalan-amalan dalam tarekat itu justru menghidupkan isi Sunnah Rasulullah SAW, yang mana telah dijanjikan oleh beliau sendiri dalam haditsnya yang tersiar : Barang siapa yang memegangi (menghidupkan) sunnah-sunnahku dimasa kerusakan (dalam akhlak)yang menimpa umatku maka ia memperoleh balasan pahala seratus orang syahid” (HR. Baihaqy dan Tabrani)

Imam Sya'rani RA. menjel;askan bahwa semua isi pelajaran,tarekat sufi itu adalah mengenai akhlaq Nabi Muhammad SAW, perjalanannya dan sunnahsunnahnya. Ketahuilah bahwa riyadhoh dan latihan jiwa itu tidak akan memberikan faedah dan tidak akan mendekatkan dirimu kepada Allah selama perbuatanmu itu belum sesuai dengan syari'ah dan sejalan dengan sunnah Rasul.

Maka dengan ini, tidaklah menjadi masalah dari mana ia mengambil pelajaran tarekat dan kepada siapa ia berguru tarekat, selama itu Mu'tabaroh, maka insyaallah akan selamat dunia hingga akherat kelak. Sehingga tidaklah mengherankan jika Jami'yyah ahlith-Thoriqoh di Indonesia menetapkan bahwa orang-orang yang, melazimkan/ merutinkan bacaan Al Qur'an dan mengamalkan sunnah Rasul termasuk golongan pengamal tarekat yang shalih, meskipun mereka tidak pernah 
melakukan bai'at atau janji untuk meng amalkan sesuatu di hadapan gurunya. Namun agar tidak tersesat dalam mempelajari tarekat dan dapat memperoleh pelajaran secara sistematis dan bertahap maka hendaknya seseorang itu mengambil seorang guru, yang mana ia belajar tarekat kepadanya.

Dalam praktek keseharian di tengah-tengah Masyarakat muslim di Indonesia, kita sering menyaksikan adanya kegiatan berjanjen, Burdahan, Diba'an atau Rotiban, yang merupakan bentuk-bentiuk amalan tarekat yang populer yang sering kali tidak memerlukan adanya baiat untuk masuk ke dalam jama'ah. Amalan ini termasuk dalam kategori tarekat non formal, yang dalam konteks pengertian yang ditetapkan oleh Jam'iyyah ahlith-Thoriqoh di Indonesia, digolongkan termasuk sebagai ahli Mulazamatil Qur'an was sunnah wa Dalailil Khoirot.

Seseorang yang masuk ke dalam Tarekat berarti secara sadar ia bertekad untuk menjalankan ajaran agama islam secara lebih berhati-hati dan teliti, sebagaimana menjauhi syubhat, menjalankan keutamaan amal-amal, seta bersungguh-sungguh dalam mengerjakan ibadahdan riadhoh. Maka kemudian Ilmu tarekat di difinisikan sebagai : "ilmu mengenai hal ikhwal nafsu-nafsu dan sifat-sifatnya manakah yang lebih tercela untuk kemudian di jauhi dan manakah yang terpuji lalu diamalkan.”

Seiring dengan perkembangan jaman yang menunjukkan gejala individualisme, rasa keterasingan manusia terhadap sesamanya kian tinggi, sehingga pada akhirnya menimbulkan kedahagaan spiritual. Berbagai jalan keluar yang ditawarkan guna mengatasi kedahagaan spiritual ini, mulai dari Yoga, Meditasi, new age spirituality dan bentuk-bentuk pelajaran mistik lainnya. Namun Islam sebagai ajaran yang sempurna telah memiliki perangkat ajaran yang bernama Tazkiyatun Nafs atau Pensucian Jiwa.

Dalam Prakteknya aplikasi Tazkiyatun nafs ini bisa bisa tarekat formal yang mensyaratkan bai'atsebagaimana yang telah kita bicarakan di muka, maupun tarekat non formal yang dewasa ini tersebar di sekitar kita . Sebagai contoh gerakan majlis dzikir Adzikra, lalu Manajemen Qolbu maupun pengamalan wirid AlMa'tsurat di kalangan umat islam Khususnya di Indonesia, merupakan 
pengejawantahan bentuk tarekat yang bersifat non formal dimana siapapun bebas untuk masuk dan keluar mengikuti kegiatan tersebut.

Ilmu Tasawuf mengajarkan moral, nilai-nilai, akhlak dan etika . Ilmu tasawuf mengajak orang bertaubat kepada Allah atas semua dosa dan kesalahan. tidak ada yang salah dari Ilmu tasawuf kecuali setelah para penyihir dan dukun datang memperkosanya. dengan meminjam istilah ilmu Tasawuf, jadilah tasawuf menjadi sebuah gerakan ilmu hitam yang penuh dengan nafsu saitani, bid'ah-bid'ah kotor dan syirik yang parah. Berbagai ilmu kadigjayaan dan kanuragan yang dimotori oleh iblis dan konconya menjadi aksesoris ilmu tasawuf . Itulah talbisnya iblis, piawai dalam hal tipu menipu terutama buat orang awam.

Kesalahpahaman terhadap tasawuf telah menyebabkan dan meluasnya pamor tasawuf yang telah diselewengkan oleh sejumlah sufi-sufi palsu (psendo-sufis), telah menumbuhkan sikap irrasional dikalangan masyarakat. tidak sedikit dari mereka yang lebih tertarik untuk mengajarkan mistik supranatural seperti keramat, kesaktian dan sebagainya ketimbang pada aspek ritual dan moralnya. Obsesi untuk memperoleh kesaktian dan kegandrungan pada hal-hal tersebut selanjutnya menyuburkan berbagai bentuk bid'ah, tahayul dan khurafat.

Disisi lain keberadaan tasawuf dan tarekat masih akan tetap dibutuhkan dan tidak akan hilang dari tradisi umat islam, karena selain membentengi hati umat islam dari dekadensi moral juga sekaligus sebagai sarana terapi ruhani yang efektif. fakta membuktikan bahwa tingkat keberhasilan metode penyembuhan ketergantungan narkoba yang dikembangkan oleh pesantren Inabah di Suralaya, maupun pesantren lain di sidoarjo dan Salatiga, ternyata memiliki tingkat efektifitas yang jauh lebih tinggi dibandingkan dengan metode rehabilitasi medis maupun detoksifikasi yang dikembangkan melalui ilmu kedokteran modern.

Mengingat kedudukan tasawuf sebagai basis spiritualitas islam yang bersifat komprehensif, maka guru besar psikologi dari California State University yang bernama Lynn Wilcox menulis buku Sufism and Psycology(1995) yang berusaha melengkapi kajian psykologi dengan metode tasawuf guna memperoleh pemahaman yang lebih tepat seputar potensi kejiwaan manusia dan jawaban atas 
kasus-kasus kejiwaan yang tidak mampu dipecahkan dengan metode ilmu psikologi konvensional.

Sementara itu, perkembangan kehidupan di era modern, telah melahirkan krisis kerohanian di kalangan umat Islam. sehingga ada kesenjangan antara praktikpraktik rohani yang Nampak dalam ajaran tasawuf yang telah tercemar dengan dinamika zaman yang menuntut adanya oase spiritual bagi orang-orang yang mengalami kekeringan jiwa, sebagai akibat pesatnya modernisasi kehidupan yang di dominasi oleh nilai-nilai matrialistik. Hal-hal inilah yang selanjutnya mendorong munculnya gerakan neo-sufi.

Menurut Nurcholis Majid, Gerakan neo-sufi di Indonesia telah mujncul ketika Prof. Hamka menulis buku "Tasawuf Modern" yang meletakkan dasar-dasar tasawuf yang baru. Buku tersebut memuat pemikiran yang memberikan apresiasi yang wajar terhadap penghayatan esoteric Islam, dengan peringatan bahwa esoterisme itu harus tetap terkendalikan oleh strandar ajaran-ajaran syari'ah. Hamka menghendaki suatu penghayatan keagamaan esoteric yang mendalam, namun tidak dengan melakukan pengasingan diri atau uzlah melainkan dengan aktif melibatkan diri dalam masyarakat.

Dalam perkembangan pemikirannya gerakan neo sufi atau tasawuf modern di Indonesia belakangan ini lebih popular dengan nama Kajian Tasawuf Positif, yang bukan hendak lari dari kenyataan duniawi yang paradox, melainkan menafsir ulang nilai-nilai Tasawuf untuk di aplikasikan dengan memberikan kontribusi nilai-nilai rohaniah untuk menghadapi permasalahan hidup di era modern .

Dalam prakteknya interpretasi nilai-nilai tasawuf dalam format yang sesuai dengan konteks zaman kekinian membuka peluang bagi pengaplikasian tasawuf positif atau neo sufi yang berkembang di Indonesia dewasa ini dalam bentuk gerakan majlis dzikir Adzikra, lalu ada pengajian manajemen qolbu, serta pengajian MABIT dan Muhasabah yang biasa diselenggarakan oleh aktifis Tarbiyah. selain itu ada juga melembaga menjadi paket paket Training dan seminar semacam ESQ(Emotional Spiritual Quotient) yang diprakarsai oleh Ary Ginanjar Agustian, Spiritual Building yang diprakarsai oleh Grup Tiga Serangkai, 
MAPPING(Membaca Ayat Pemikiran Perencanaan Inspirasi Gerak) yang diprakarsai oleh Heru SS dari Trustco, Pelatihan Sholat Khusyu' oleh Ustadz Abu Sangkan dan lain-lain yang mengajarkan bentuk kesufian praktis di era Modern.

\section{KESIMPULAN}

Berdasarkan uraian di atas dapat disimpulkan sekali lagi bahwa cita-cita orang yang mendalami tasawuf maupun bertarekat ternyata tidaklah menyimpang dari norma-norma ajaran Islam, bahkan dengannya seseorang akan berkomitmen meniru akhlak generasi salaf. Adapun keganjilan-keganjilan yang mungkin dijumpai pada praktek sufi dan tarekat dewasa ini, lebih disebabkan oleh perbedaan setting sosial dan pemikiran antara masa kita dengan masa ketika ajaran tasawuf maupun pelembagaan metode tgarekat itu disampaikan oleh pendirinya. Yang perlu dilakukan ialah menginterpretasikan kembali pikiran-pikiran dan ajaran yang terkandung di dalamnya lalu merekonstruksinya sesuai dengan pola pikiran manusia dewasa ini.

\section{DAFTAR PUSTAKA}

A. Purwadaksi bin Abu Bakar Saleh, Tarekat dan Masa depannya dalam buku Rekontruksi dan Renungan Religius Islam, Paramadina,cet I, Jakarta 1996

Abu Al-Wafa'al-Ghanimi Al-Taftazani, Sufi dari zaman ke zaman, Pustaka, Cet, 1, Bandung, 1985.

Ahmad Najib Burhani, Tarekat Tanpa Tarekat;Jalan Baru Menjadi Sufi,Serambi, Cet.I, Jakarta,2002.

Haidar Baqir, Tasawuf Positif: Alternatif Spiritual Bagi Masyarakat Modern, artikel dalam jurnal PESAN, No. 58, Th 2, 02/2002

Masruri Abdul Mughni, Tarekat dan Problem Kemodernan Pendidikan, Makalah Seminar Nasional Tarekat dan Modernitas, STAIN Pekalongan, 27 Pebruari 2000.

Nurcholis Madjid Sufisme Baru dan Sufisme Lama:Masalah Kontinuitas dan Perkembangan Dalam Esoterisme Islam, Makalah Seminar.

Syaikh Abdurrahman Abdul Khaliq, Penyimpangan-penyimpangan Tasawuf, Robbanni Press, cet I, Jakarta, 2001. 
Syaikh Muhammad Amin al-Kurdi, Tanwiirul Quluub fii Mu'amalati'allamil Ghuyuub, Daarul Fikr, Beirut, 1994.

Tim Pustaka Widuri, Agenda Thoriqoh, Pustaka Widuri, Sukoharjo,tt 